\title{
The Impact of Occupational Stress on Job Satisfaction Among Kenyan Primary School Teachers
}

\author{
Emily Jepkoech Koros, John M. Momanyi, Carolyne K. Chakua
}

Part time lecturer and Ph. D. candidate, Educational Psychology Department, Moi University, Eldoret, Kenya Educational Psychology Lecturer, Educational Psychology Department, Bomet University College, Bomet, Kenya

Educational Psychology Lecturer, Educational Psychology Department, Moi University, Eldoret, Kenya

\begin{abstract}
Teaching profession has been hit by high teacher turnover and attrition resulting in shortage of teachers in primary schools. The purpose of this study was to determine the impact of occupational stress on job satisfaction among primary school teachers in Nandi County, Kenya. The main objective was to find the relationship between occupational stress and job satisfaction. This study adopted the explanatory survey research design. The study targeted a total of 1652 primary school teachers. Simple random sampling technique was used to select a sample of 312 teachers. The main data collection instrument was a questionnaire for the teachers. The data collected was analysed through the use of SPSS by regressing and correlating occupational stress and job satisfaction in order to determine the strength of the relationship. The study results indicated that there was a positive relationship between occupational stress and job satisfaction $(\beta=.527, \mathrm{p}=.000)$. The coefficient of determination $\left(\mathrm{R}^{2}=.452\right)$ for the estimated model indicated that $45.2 \%$ of the deviations in occupational stress contribute towards job satisfaction among primary school teachers. A majority of the primary school teachers are dissatisfied with teaching and if given an opportunity would leave teaching for other professions. The study recommends that it is imperative of government and other stakeholders in education to ensure a high level of career satisfaction for highly qualified and experienced teachers.
\end{abstract}

Keywords: Teaching profession, occupational stress, primary school teachers, job satisfaction, Kenya.

\subsection{Introduction}

Teaching has become a more demanding and intense job. It has been identified as one of the professions associated with very high levels of occupational stress (Acirrt, 2002). Teacher job satisfaction has been the focus of considerable literature (Dinham \& Scott, 2000; Woods \& Weasmer, 2004). The relationship of job satisfaction to occupational stress and other negative factors such as intention to leave teaching has been studied in various circumstances (De Nobile, 2005; Abdulkadir 2013). Singh and Valsaraj (2011) studied the comparison of the occupational stress among teachers in different schools in Uttar Pradesh, India and found out that there was a significant difference in occupational stress of teachers in different schools. Higher levels of occupational stress have been associated with poor teacher performance, absenteeism and leaving the job (Kyriacou, Kunc, Stephens \& Hultgren, 2003).

Occupational stress is known as stress at work. It occurs when there is a discrepancy between the demands of the workplace and that of individual's (Tsutsumi, Nagami, Yoshikawa \& Kogi, 2009). Occupational stress has been defined as the experience of negative emotional states such as frustration, worry, anxiety and depression attributed to work related factors (Kyriacou, 2001). Occupational stress in the human service professions, particularly among teachers, has been a focus of study in the last two decades. Most surprisingly, school teachers have been considered to be under stress (Ghani, Ahmad \& Ibrahim, 2014), undergoing the process of stress or suffering from depressive symptoms (Kyriacou, \& Chien, 2009). There exists a substantial body of literature describing teaching as stressful occupation and suggesting that teacher stress appears to be an increasing problem (Antoniou, Polychroni, \& Vlachakis, 2006). A number of 
factors have been shown to influence teachers' decisions about staying on or leaving the profession, including job stress, job satisfaction, resilience and self-efficacy (Chan, Lau, Nie, Lim, \& Hogan, 2008). Typically, they include stressors in the areas of work role (workload); administration; class size; role ambiguity and conflict, the pressures of the teachers' roles; poor working conditions; little recognition and low remuneration; lack of involvement in decision-making; student rebellion; lack of effective communication, as well as the many emotional demands of teaching (Brown \& Ralph, 1992; Cooper \& Kelly, 1993).

\subsection{Literature Review}

Teaching has become a more demanding and intense job. It has been identified as one of the professions associated with very high levels of occupational stress (Acirrt, 2002). Teacher job satisfaction has been the focus of considerable literature (Dinham \& Scott, 2000; Woods \& Weasmer, 2004). The relationship of job satisfaction to occupational stress and other negative factors such as intention to leave teaching has been studied in various circumstances (De Nobile, 2005; Abdulkadir 2013). Singh and Valsaraj (2011) studied the comparison of the occupational stress among teachers in different schools in Uttar Pradesh, India and found out that there was a significant difference in occupational stress of teachers in different schools. Higher levels of occupational stress have been associated with poor teacher performance, absenteeism and leaving the job (Kyriacou, Kunc, Stephens \& Hultgren, 2003).

Occupational stress is known as stress at work. It occurs when there is a discrepancy between the demands of the workplace and that of individual's (Tsutsumi, Nagami, Yoshikawa \& Kogi, 2009). Occupational stress has been defined as the experience of negative emotional states such as frustration, worry, anxiety and depression attributed to work related factors (Kyriacou, 2001). Occupational stress in the human service professions, particularly among teachers, has been a focus of study in the last two decades. Most surprisingly, school teachers have been considered to be under stress (Ghani, Ahmad \& Ibrahim, 2014), undergoing the process of stress or suffering from depressive symptoms (Kyriacou, \& Chien, 2009). There exists a substantial body of literature describing teaching as stressful occupation and suggesting that teacher stress appears to be an increasing problem (Antoniou, Polychroni, \& Vlachakis, 2006). A number of factors have been shown to influence teachers' decisions about staying on or leaving the profession, including job stress, job satisfaction, resilience and self-efficacy (Chan, Lau, Nie, Lim, \& Hogan, 2008). Typically, they include stressors in the areas of work role (workload); administration; class size; role ambiguity and conflict, the pressures of the teachers' roles; poor working conditions; little recognition and low remuneration; lack of involvement in decision-making; student rebellion; lack of effective communication, as well as the many emotional demands of teaching (Brown \& Ralph, 1992; Cooper \& Kelly, 1993).

Studies on the relationship between teachers' occupational stress and their qualification have shown that postgraduate teachers have significantly less job satisfaction on job role item than the undergraduate and graduate teachers (Mondal, Shrestha, \& Bhaila, 2011). Hong Kong teachers without finishing professional training and of junior rank reported themselves to be more stressed in a study by Lau, Yuen and Chan (2005). Quite opposite to this, in a separate study by Lam (2006) teachers' qualification was not correlated to their stress level. Other data support no significant difference between stress and academic qualifications of the teachers (Mokdad, 2005). The early years of a teacher's career have been recognized as being stressful. Contrary to this, the year of experience on the school teachers did not show any significant effect on job satisfaction and occupational stress in another study (Johannsen, 2011; Jepson \& Forrest, 2006; Chona \& Roxas, 2009). Also, low wages and limited opportunities for promotion, teachers' goals (occupational and financial) have been identified as a source of stress for Greek primary and secondary teachers (Koustelios \& Kousteliou, 1998).

In Kenya, there is high teacher turnover and attrition that is attributed to poor working conditions which include poor remuneration and work overload. In addition, most teachers are assigned 35 lessons per week which to teachers is considered an overload (Bennel, 2004). Research by Crossman and Harris (2006) indicate that the degree to which teachers are satisfied with their jobs and working conditions is likely to have significant effects for the retention of teachers within the profession. This shows that most studies on occupational stress and job satisfaction has been done in the health sector and education sector.

However, this study will therefore attempt to establish the impact of occupational stress on job satisfaction.Further, there is no published systematic study on why most teachers want to quit teaching for 
other jobs which this study investigated. Therefore, this study determined to find the correlation between occupational stress and job satisfaction among Kenyan primary school teachers in Nandi County.

\subsection{Relationship between Occupational Stress and Job Satisfaction}

Johnson and Holdaway (1994) explored job satisfaction among elementary and junior high school principals in Alberta, Canada. The authors argue that in view of the changing role of school principals, studies of job satisfaction and the importance of job facets for satisfaction are urgently needed. Important areas to focus on include involvement in the hiring of staff and the performance of students and teachers.

Some studies have explored the association between job satisfaction and stress. De Nobile and McCormick (2005) investigated the relationships between job satisfaction and occupational stress among Catholic primary schools in New South Wales, Australia. They found that four stress domains (information domain, personal domain, student domain, and school domain) were determinant $s$ of job satisfaction. Negative associations were found between job satisfaction and occupational stress. Sources of stress included lack of support from school administration, supervision, the staff-headteacher relationship and staff student relationships.

\subsection{Hierarchy of Need Theory}

Maslow (1954) believed that in the quest to fulfill the needs, individuals behave and exhibit in a certain manner. Human gets satisfaction only when their needs is fulfilled. His theory has three assumptions, namely, human needs never ends, when one needs is fulfilled, the next hierarch of needs to be fulfilled as soon as to be satisfied and lastly human needs can be divided in to various level depending the importance as and when the lastly level of need is fulfilled, the next level needs to be scaled and fulfilled to derive satisfaction. The hierarchy of needs identifies five distinct levels of individual needs. These include physiological, safety, social, esteem and self-actualization needs.

According Maslow's theory people would first want to have these needs fulfilled before they move on to the next level of needs. Safety needs include the need for security, protection and stability in the physical and interpersonal events of day to day life. According to this theory people want to feel safe, secure, and free from fear. In this regard, they need stability, structure, and order. In the workplace, job security and fringe benefits, along with an environment free of violence, fills these needs. The theory reiterates that individuals would want to satisfy safety needs only if their basic biological needs have been satisfied. Social needs involve the need for love, affection, a sense of belonging in onese relationships with others.

Daft (1997) also explained this need by writing that it involves the need for friends, family, and intimacy for social acceptance and affection from one's peers. In the workplace, this need is satisfied by participation in work groups with good relationships among co-workers and between workers and managers. Esteem needs include the need for status, recognition and achievement. People want the esteem of others and they want to be regarded as useful, competent, and important. People also desire self-esteem and need a good self-image. In the workplace, increased responsibility, high status, and recognition for contributions satisfy these needs. Self-actualization is the highest motivation level according to Maslow's hierarchy of needs. This involves people striving to actualize their full potential, in order to become more of what they are capable of being. They seek to attain self-fulfillment. In the workplace, people satisfy this need by being creative, receiving training, or accepting challenging assignments (Daft, 1997)

Maslow's need hierarchy illustrates Maslow's conception of people satisfying their needs in a specified order from bottom to top that is people are motivated to satisfy the lower needs before they try to satisfy the higher needs. Once a need is satisfied it is no longer a powerful motivator.

It is only after the physiological and safety needs are reasonably satisfied do the higher-level needs: social, esteem, and self-actualization become dominant concern (Bateman \& Snell, 2009). Schermerhom, Davidson, Poole, Woods, Simon, \& McBarron (2004) add that, Maslow assumes that some needs are more important than others and must be satisfied before other needs. The theory states that individuals experience a hierarchy of needs, from lower level to higher level of psychological needs. One has to satisfy the current needs before going to the next level of needs. For example, physiological needs must be satisfied before safety needs can be attended to. Thus, the theory assumes that the fulfillment of each need level suggest satisfaction. Using Maslow's theory managers can motivate and ensure job satisfaction in their employees by making sure that each individual need level is satisfied. Satisfaction of such needs can be done through 
offering suitable rewards. For example, managers can satisfy employee's physiological needs through provision of accommodation and a staff canteen. Similarly, employee security needs can be satisfied through ensuring that employees are given salaries, retirement annuity and medical benefits. For social needs, managers can ensure employee job satisfaction by encouraging social interaction amongst employees. Managers can design challenging jobs, delegate responsibility and encourage participation in decision making in order to satisfy employees ${ }^{\text {ee }}$ esteem needs. The needs for self-actualization can be satisfied through the provision of executive training, provision of challenges and encouraging creativity.

\subsection{Research Methodology}

This study adopted explanatory survey research design. The objective is to study a situation or a problem in order to explain the relationships between the variables. This design makes comparisons and evaluation of existing conditions as well as collection of factual information in their natural setting through the use of the questionnaire (Hyz, 2010). The study targeted all primary school teachers in Nandi North Sub-County, Nandi County, Kenya. The target population of this study included all the 1652 teachers. A sample size of 312 teachers was chosen by simple random sampling. A questionnaire was used to collect primary data. An Organizational Stress Screening Tool (ASSET) developed by Cartwright and Cooper (2002) was used to measure occupational stress. Job Satisfaction was measured using a 36-item instrument of a modified version of Job Satisfaction Survey (JSS) by Spector (1997). The Likert scales ranged from 1 (Strongly Disagree) to 7 (Strongly Agree). Construct validity of the questionnaire was verified by factor analysis and by measuring the internal consistency of the single scales. Cronbach Alpha Coefficient was used to test on the reliability of the questionnaire. The Statistical Package for Social Sciences (SPSS) software was used to analyze the data obtained from the questionnaire. The SPSS software.enables the researcher to use regression analysis to estimate the relationships between the variables. The data was presented in form of tables.

\subsection{Findings and Analyses}

\subsection{The Relationship between Occupational Stress and Job Satisfaction}

The hypothesis $\mathbf{H O}_{1}$ states that there was no significant relationship between occupational stress and job satisfaction. The regression coefficient results are shown in table 1 . The result shows a strong positive relationship as proved by a standardized regression coefficient of $\beta=.527, p=.000$. Therefore the hypothesis is rejected indicating that there is relationship between occupational stress and job satisfaction.

Table 1 Regression Coefficient Results

\begin{tabular}{|c|l|l|l|l|l|l|}
\hline \multicolumn{2}{|c|}{ Model } & Unstandardized Coefficients & Standardized Coefficients & $\mathrm{t}$ & sig \\
\hline \multirow{2}{*}{1} & $($ Constant $)$ & $\beta$ & Std. error & Beta & & \\
\cline { 2 - 7 } & Occupational stress & 1.548 & .183 & & 8.458 & .000 \\
\hline \multicolumn{2}{|l|}{ a. Dependent Variable: Job satisfaction } & .537 & 1.323 & .000 \\
\hline
\end{tabular}

Table 2 The Model Summary for Occupational Stress and Job Satisfaction

\begin{tabular}{|l|l|l|l|l|}
\hline Model & $\mathrm{R}$ & $\mathrm{R}^{2}$ & Adjusted $\mathrm{R}^{2}$ & Std. error of the estimate \\
\hline 1 & .527 & .452 & .450 & .105 \\
\hline \multicolumn{4}{|c|}{ a. Predictors: (control), Occupational stress } \\
\hline
\end{tabular}

Table 2 shows the results from the model summary. The result shows that R squared is .452 which means that $45.2 \%$ of the deviations in occupational stress contribute towards job satisfaction among primary school teachers.

\subsection{Discussion of Results}

The findings show that there is a positive relationship between occupational stress and job satisfaction as shown by the standardised coefficient of $\beta=.527, \mathrm{p}=.000$ and the $\mathrm{R}$ squared is $45.2 \%$ as shown in table 2 . This result is contrary to a study by De Nobile and McCormick (2005) who investigated the relationships between job satisfaction and occupational stress among Catholic primary schools in New South Wales, 
Australia. They found that four stress domains (information domain, personal domain, student domain, and school domain) were determinants of job satisfaction. Negative associations were found between job satisfaction and occupational stress. Sources of stress included lack of support from school administration, supervision, the staff-headteacher relationship and staff student relationships. In this study there was a positive association.

\subsection{Conclusion and Recommendations}

In conclusion occupational stress has a bearing on job satisfaction among primary school teachers in Kenya. The respondents indicated that occupational stress hampered their job satisfaction levels. This implies that majority of the primary school teachers are dissatisfied with teaching and if given an opportunity would leave teaching for other professions. Sodoma and Else (2009) have noted that occupational stress is associated with low career satisfaction and this has a special significance in teaching profession where staff members experience both psychological and physical stress. Sodoma and Else (2009) have noted that occupational stress is associated with low career satisfaction and this has a special significance in teaching profession where staff members experience both psychological and physical stress. This shows that primary school teachers are not satisfied with teaching profession. One of the ways to ensure a high level of satisfaction for these teachers is by enhanced salary. This is needed to satisfy the materialistic need of the teachers and also improve the public image and self-esteem of teachers. Better working conditions are also advocated. These measures are necessary in order to ensure highly qualified and very experienced teachers are retained in the schools. It is also important to note that implementation of these measures will minimize teachers' turn over and burnout. The contribution of these findings is that it is imperative of government and all stakeholders in education to ensure a high level of career satisfaction for highly qualified and experienced teachers.

\subsection{References}

1. Abdulkadir Ç. (2013). The Examining of Job Satisfaction Level of Koran Teachers in Terms of Some Variables. Journal of Education and Learning. Vol.7 (4) pp. 199-204.

2. Acirrt, T. (2002). Focus Groups with Teachers in Catholic Systemic Primary Schools. Sydney: University of Sydney Research Training and Information Services on the World of Work.

3. Antoniou, A. S., Polychroni, F., \& Vlachakis, A. N. (2006). Gender and age differences inoccupational stress and professional burnout between primary and high-school teachers inGreece. Journal of Managerial Psychology, 21 (7), 682-690.

4. Bateman, T., \& Snell, S., (2009). Management: Leading and collaborating in a competitive world. Boston: McGraw-Hill.

5. Bennell, P. (2004). Teacher motivation and incentives in Sub-Saharan Africa and Asia Knowledge and Skills for Development, Brighton.

6. Brown, M., \& Ralph, S. (1992). Teacher stress. Research in Education, 4,103-110.

7. Cartwright, S., \& Cooper, C. L. (2002). ASSET: An Organisational Stress Screening Tool. The Management Guide. Manchester, UK: RCL Ltd.

8. Chan, W. Y., Lau, S., Nie, S. L. Y., Lim, S., \& Hogan, D. (2008). Organizational an personal determinant $\mathrm{s}$ of teacher commitment: The mediating role of teacher efficacy and identification with school. American Educational Research Journal, 45, 597-630.

9. Chona, C., \& Roxas, M. A. (2009). Stress among public elementary school teachers. University of the Cordilleras Research Journal, 1(4), 86 - 108.

10. Cooper, C. L. \& Kelly, M (1993). Occupational stress in head teachers: A national UK Study. British Journal of Educational Psychology, 63, 130-143.

11. Crossman, A. \& Harris, P. (2006). Job satisfaction of secondary school teachers, Educational Management Administration Leadership, 34 (1), 29-46.

12. Daft, R. L. (1997). Understanding Management. New York: Dryden Press

13. De Nobile J. (2005). Managerial Communication in Primary Schools. The Australian Educational Leader, 27 (1), 24-27. 
14. De Nobile, J. J., \& McCormick, J. (2005), Job satisfaction and occupational stress in Catholic primary schools, a paper presented at the Annual Conference of the Australian Association for Research in Education, Sydney, November 27th-December 1st, 2005.

15. Dinham, S. \& Scott, C. (2000). Moving into the third outer domain of teacher satisfaction. Journal Educational administration, 38 (4), 379- 396.

16. Ghani, M. Z., Ahmad, A. C \& Ibrahim, S (2014). Stress among Special Education Teachers in Malaysia. Procedia - Social and Behavioral Sciences1 14, 4- 13.

17. Hyz, A. (2010). Emotional Intelligence and Employee Performance of Greek Banking Staff: An Empirical Investigation. Acta Universitatis Lodziensis, 2(3), 85-96

18. Jepson, E., \& Forrest, S. (2006). Individual contributory factors in teacher stress: The role of achievement striving and occupational commitment. British Journal of Educational Psychology, 76, 183-197.

19. Johannsen, S. E. (2011). An analysis of the occupational stress factors identified by certified teachers. Electronic Theses \& Dissertations. Education Administration Dissertations. http://hdl.handle.net/10518/3842.

20. Johnson, N. A., \& Holdaway, E. A. (1994), Facet importance and the job satisfaction of school principals, British Educational Research, 20, 1, 17-33.

21. Koustelios, A., \& Kousteliou, I. (1998). Relations among measures of job satisfaction, role conflict, and role ambiguity for a sample of Greek teachers. Psychological Reports, 82, 131-136.

22. Kyriacou, C., \& Chien, P. Y. (2009). Teacher stress in Taiwanese primary schools. The Journal of Educational Enquiry, 5(2).

23. Kyriacou, S., Kunc, R., Stephens, P., \& Hultgren, A. (2003), Student teachers' expectations of teaching as a career in England and Norway. Educational Review, 55, 255-263.

24. Kyriacou. C. (2001). Teacher stress: directions for future research. Educational Review, 53, (1), 2735.

25. Lam, Y. M. L. (2006). Teacher stress encountered by Hong Kong secondary and primary school teachers: Similarity and Disparity. A Dissertation submitted in partial fulfillment of the requirements for the degree of Master of Education in Faculty of Education, the University of Hong Kong.

26. Lau, P., Yuen, M., \& Chan, R. (2005). Do demographic characteristics make a difference to burnout among Hong Kong secondary school teachers? Social Indicators Research Series, 25, 491-516.

27. Maslow, A. H. (1954). Motivation and Personality. New York: HarperCollins Publishers.

28. Mokdad, M. (2005). Occupational stress among Algerian teachers. African Newsletter on Occupational Health and Safety, 15(2), $46-47$.

29. Mondal, J., Shrestha, S., \& Bhaila, A. (2011). School Teachers : Occupational stress and Job Satisfaction, Kaski, Nepal. International Journal of Occupational Safety and Health, 1, 27-33.

30. Schermerhom, J. R., Davidson, P., Poole, D., Woods, P., Simon, A., \& McBarron, E. (2014). Management. Milton QLD, Australia: John Wiley and Sons.

31. Singh, J, \& Valsaraj, K. M (2011). Occupational stress of physical education teachers in different management schools in Uttar Pradesh: a comparative study: Indian Journal of Movement Education and Exercises Sciences (IJMEES), 1 (1).19-22.

32. Sodoma, B. \& Else, D. (2009), Job satisfaction of Iowa public school principals. The Rural Educator, 31, (1), 10-18.

33. Spector, P. E. (1997). Job satisfaction: Application, assessment, causes, and consequences. London: Sage.

34. Tsutsumi, A., Nagami, M., Yoshikawa, T. \& Kogi, K, (2009). Participatory intervention for workplace improvements on mental health and job performance among blue-collar workers: a cluster randomized controlled trial. Journal of Occupational and Environmental Medicine, 51(5),554-63.

35. Woods, A. M., \& Weasmer, J. (2002). Maintaining job satisfaction: Engaging professionals as active participants. The Clearing House. 75(4), 186 - 189. 